\title{
The Effect of Using Mobile Applications (GeoGebra and Sketchpad) on the Students' Achievement
}

\author{
Mohammad Ahmad Alkhateeb ${ }^{{ }^{*}}$, Ahmed Mohammad Al-Duwairi ${ }^{2}$ \\ ${ }^{1}$ Hashemite University, Zarqa, JORDAN \\ ${ }^{2}$ AL- Albayt University, Mafraq, JORDAN \\ *CORRESPONDENCE: M MKM7879@yahoo.com
}

\begin{abstract}
Mobile devices are characterized by attractive advantages, and provide broad benefits in the university students' math teaching. Our study proposes integrating the Mobile Applications in teaching geometry. Findings of the researches showed that students face difficulties in learning geometry. The material and virtual maneuvers may assist the university students in learning and understanding geometry easily. In this research, we investigated the effects of Mobile Applications (GeoGebra and Sketchpad) on the Students' Achievement. In this concern, we prepared the educational materials, achievement exams and worksheets according to the university curriculum. And they were applied on the students. This quasi-experimental study was applied on 105 students. The results showed that the use of Sketchpad and GeoGebra facilitated the students' understanding of the geometry concepts. Furthermore, the results showed that GeoGebra had more effect than Sketchpad on the students' learning.
\end{abstract}

Keywords: mobile devices, GeoGebra, Sketchpad, geometry

\section{INTRODUCTION}

Mobile devices are a part of the daily life of the students inside and outside the classroom. Other techniques such as the paper and pencil and the computer programs are also acceptable. Nonetheless, most of the current generation in the schools and universities cannot see the world without mobile technology (Dias \& Victor, 2017; Grant, Tamim, Sweeney, Ferguson \& Jones, 2015).

With the progress in the technological change process in the education field, we ought to admit that the mobile education is a part of a new scene. It provides personal distant learning, non-official learning and automatic learning through the use of mobile devices by students of all ages and backgrounds. It enables them to interact, cooperate and learn through different ways (Thomas \& Muñoz, 2016).

Walker's results (2013) showed that math teachers were interested in the use of the mobile in math learning. From their point of view, this technology can increase the students' motivation and participation in math learning and provide various ways in math teaching. In addition, the students' motivation improved when they used the mobile. (Zaranis, Kalagiannakis \& Papadakis, 2013). Another study showed that the mobile learning application stimulate the students, which makes math more "learnable", enjoyable and interactional (Supandi, Ariyanto, Kusumaningsih \& An, 2017).

The results, also, showed that the mobile devices were a viable alternative of the desktop computers for helping in conceptualizing and understanding the math concepts. Meanwhile, the mobile devices were used to promote the collaborative learning environments, which indicated the mobile devices' abilities to narrow the

Article History: Received 3 February $2019 \bullet$ Revised 20 February $2019 \bullet$ Accepted 21 February 2019

(C) 2019 by the authors; licensee Modestum Ltd., UK. Open Access terms of the Creative Commons Attribution 4.0 International License (http://creativecommons.org/licenses/by/4.0/) apply. The license permits unrestricted use, distribution, and reproduction in any medium, on the condition that users give exact credit to the original author(s) and the source, provide a link to the Creative Commons license, and indicate if they made any changes. 
gap between the school math and the world; as compared with the schoolbooks. Consequently, an interactional math model of the applications of the mobile learning, which are run by Apple or Android systems by using the web services, can facilitate realistic learning everywhere (Galligan, Loch, McDonalr \& Tayler, 2010; Thomas \& Muñoz, 2016).

Many educators believe that the mobile devices are among the best educational vehicles in teaching mathematics because they have various instruments and techniques to perform an effective role in teaching vital and realistic mathematics, renewing methods of teaching and applying the different educational strategies. They, further, help in attracting the students' attention, applying modern teaching vision, providing prompt feedback to the students and contributing in giving realistic solutions for the educational problems they face (Hohenwarter \& Lavicza, 2007; Kebritchi, Hirumi \& Bai, 2010; Li \& Ma, 2010; Zhao \& Okamoto, 2009).

Therefore, we find that the math teaching-learning approach is closely and strongly tied to the modern technology particularly in the mobile devices. Technology provides dynamic software instruments that are directed to math teaching-learning within contexts that enable students understand math in a meaningful manner. As a result, the educational Applications in the mobile devices enable the students to interact with these devices to a wide extent, link the information and represent them in different types and shapes (Abramovich, 2013; Chaamwe, 2010; Hollebrands, 2007).

The mobile devices- with their modern applications- contributed in providing interactive and dynamic educational environment, which enabled the students to implement the exercises, problems and tasks, and develop the students' abilities to maximize the use of such modern techniques in their learning. Baki, Kosa and Guven (2011), and Gürsul and Keser (2009) see that such mobile devices applications saved the efforts spent to make the student acquires basic learning skills in comparison with the conventional methods currently applied in math teaching.

Due to the vital importance of this technology in math teaching, the National Council of Teachers of Mathematics (NCTM) called for building educational policies that utilize technology in math teaching through the use of the smart devices and their different applications. Thereby, students receive teaching programs in mathematics to a wide extent, due to the ability of technology to promote the students' learning through the embodiment of the math ideas in visible shapes. They, also, facilitate data organization, storing, analysis and retrieval in different ways, and apply the arithmetic operations with accuracy and efficiency. Therefore, NCTM (2000) adopted technology within the principles upon which the school math is based.

Because of the multiple programming languages, differences of their levels, and existence of specialized companies in education and qualified cadres in the mobile devices and mathematical areas, there are large numbers of different educational applications that cover all the math aspects. Still, there are specialized Applications in specific domains branches of mathematics. Such Applications compete in providing effective programming tools that teach specific subjects. For instance, there are Applications specialized in graphics, others in geometry, and so on, which are suitable for the different age groups (Korenova, 2012; Li, 2007).

Sketchpad Application is one of the important Application in math teaching, which was introduced for the first time in the United States of America in 1991 by its designer, Nicholas Ackie. It was based on the idea that the use of computer in education is a must so The program was developed as part of the Visual Geometry Project, when its designer joined the project and added a meaningful development to the program, untill he approached its initial version. Sketchpad is also the most important interactional geometry program, which fosters building all the 2D (two dimensional) formats, where the user can move and activate the figures and formats to discover their characteristics. The Application provides the user an advanced calculator to carry out the arithmetic operations, draw all the conjunctions and find their equations (Leong, 2013).

This Application was specially designed to learn the geometrical concepts; as it offers a study of problemsolving and a study of the conventional mathematics. It consists of a learning environment controlled by the students, where they tackle multiple things through available operations according to a number of determinants that control the operations to discover the relationships. Students are encouraged to explore and identify many Application functions through organization, explication, trial and error, induction and conclusion, data translation into a certain prognosis, and generalization of their results. It is an ideal Application for interactive learning; because the collaborative environment, it provides has the ability to promote the student's shift from the material experience in math to levels that are more than abstraction, to develop their intuitive spirit and improve their thinking (Gemechu, 2017). 


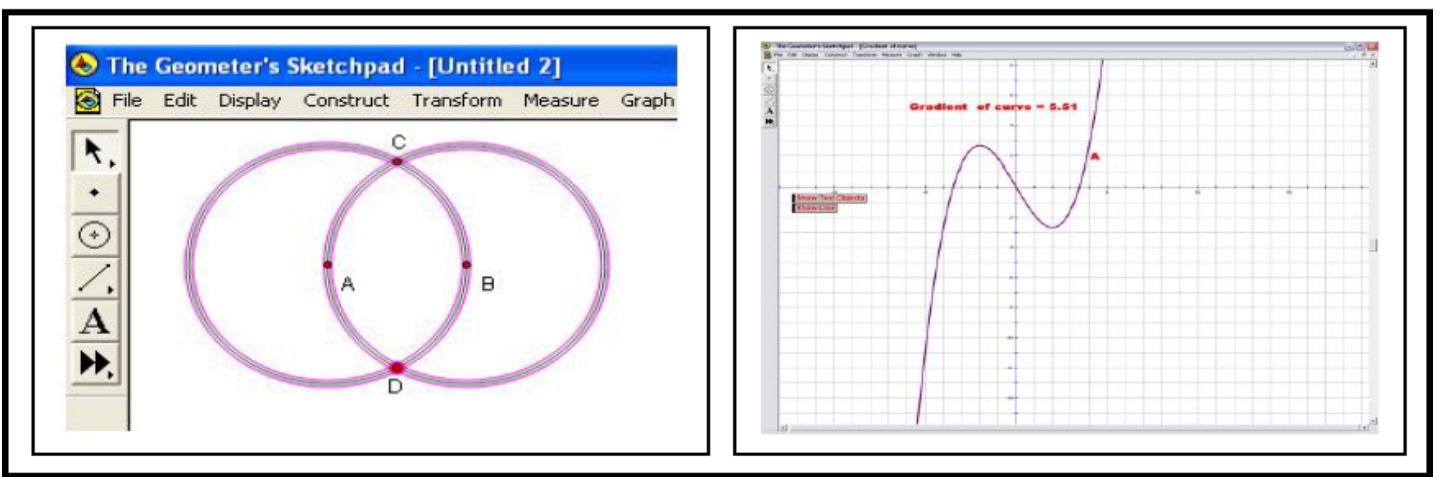

Figure 1. Kinds of the geometrical figures produced using Sketchpad

Gecu and Satici (2012), Leong (2013) and Ruthven and Hennessy (2003) indicated that the use of Sketchpad supports listening in teaching and good understanding of the geometrical concepts. The interactive environment the Application offers helps teachers motivate their students to intuition, guess and explore the geometrical relationships. The Application could be downloaded from the free website of the company on the following link: https:/www.dynamicgeometry.com, or through Google Play or App Store. Figure 1 shows kinds of the geometrical figures produced using the Sketchpad.

On the other hand, GeoGebra is also one of the most modern interactional Applications that were introduced to math learning-teaching. It is a free Application that serves more than fifty languages, and could be downloaded on computers or mobile telephones. It serves all the math disciplines (algebra, geometry, measurement, statistics and probabilities). It connects these branches in a manner that enables the learner to discover learning by him/herself. It could be used at all the educational stages from the elementary through university education and even could be used by the post graduate students. The Application could be downloaded through the following link: https://www.geogebra.org, or through Google Play or App Store. The website is characterized by the possibility of logging in, allows the user to publish his/her works and share with others, which enables him/her utilize their experiences and views.

GeoGebra is based on the math scientific criteria, and was designed by Markus Hohentwrter. Thereafter, it was developed by a team of programmers from Florida Atlantic University, and designed in a way that enables the students develop an in-depth understanding of the mathematical theories and facts practically. It also enables them discover these theories and facts by their own. The Application consists of a number of tools that contribute to the student's acquisition of math skills, which include all the facilities that make the learning process interesting and easy.

Saha, Ayub and Tarmizi (2010) conducted a study aimed at identifying the effect of the use of a GeoGebra on teaching the coordinate geometry on a group of the secondary stage students. The results showed statistically significant differences between the means of the two groups in the post-test in favor of the GeoGebra group, and the effect size was moderate.

Bhagat and Change (2015), Emaikwu, Lji \& Abari (2015), and Shadaan and Leong (2013) indicated that the use of GeoGebra assisted the learner build the new learning and connect it with previous learning, which is quite consistent with the constructive approach of learning. In addition, it could enhance the students' ability to conceptualize the math elements, and consequently improve the learning.

Zengin, Furkan and Kutluca (2012) addressed the characteristics and advantages of the GeoGebra as follows: It is a dynamic mathematical Application valid for education Applications in the elementary, secondary and university stages. It combines algebra, geometry, and calculus. Therefore, it is a dynamic geometry Application that enables the learners create points, vectors, lines, conical parts as well as conjunctions, and then change them effectively. Meanwhile, the coordinates and equations could be entered directly. As a result, GeoGebra has the ability to deal with other variables, points and vectors. To find the derivatives and integrations, and offer other orders, such as roots and exponents. It also has other advantages, as each element in the geometry window has a statement in algebra window, and vice versa. The Application has an interface on a screen designated for drawing and other screen for algebra. Algebra inputs, orders and equations may be entered directly in the "enter" field using the keyboard. Then, all the drawing elements appear on the drawing screen, and all the algebraic figures appear on algebra screen and the Application interface in a flexible manner, which is adaptable to all the student needs. The following figures show the 


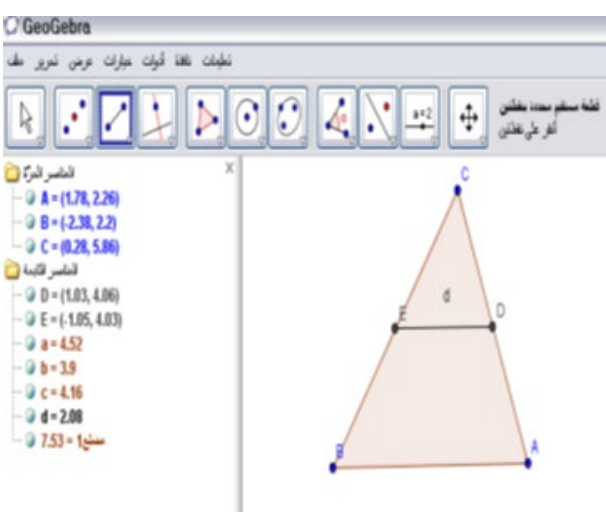

Explains drawing a Triangle

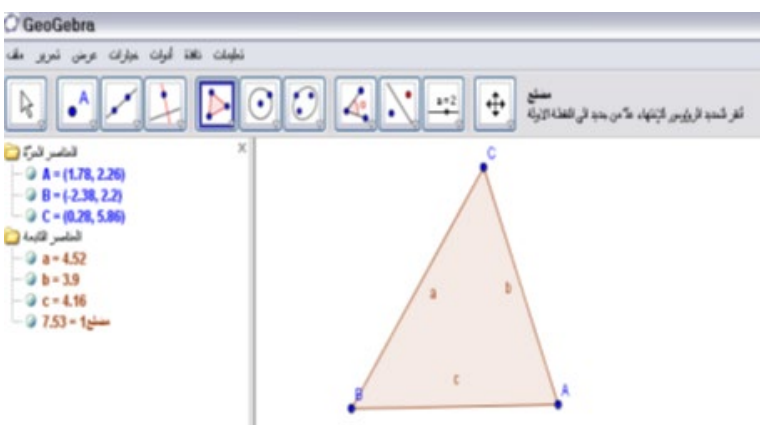

Midpoints of the two sides of the triangle and straight segment connecting between them

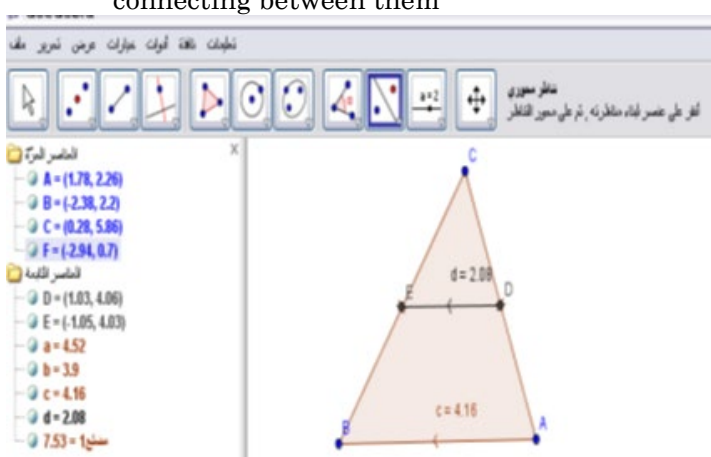

Control in colors, lengths, parallels and showing the value

Explains D Inclination and C Inclination

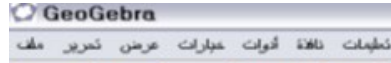

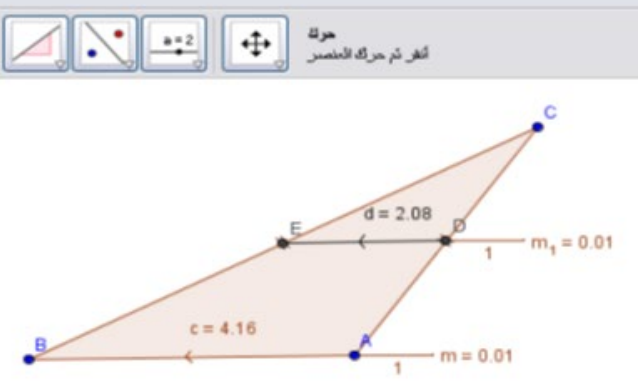

Explains the stability of relationship no matter where the Point $\mathrm{C}$ is moved

Figure 2. Steps to find the relation between the straight segment connecting between the two midpoints of the two sides of the triangle with the third side using GeoGebra

steps to find the relation between the straight segment connecting between the two midpoints of the two sides of the triangle with the third side using GeoGebra.

While admitting the importance of the role of geometry, many studies emphasized that its learning is facing many difficulties. Its teaching did not succeed in achieving its desired objectives, and it is one of the most difficult math branches the students face. This is apparent in their poor achievement in this discipline. Arbain and Shukor (2015), Zakaria and Lee (2012) see that the reason of these difficulties is ascribed to the ways the geometry topics are taught.

NCTM (2000) standards indicate that students are unable to understand the geometrical figures and their properties. They also indicate that their poor understanding of the concepts, characteristics, and relationships. In addition, their low abilities in problem-solving, is due to the applicable teaching methods. Therefore, it is 
inevitable to find new ways and methods in math teaching, in an attempt to decrease the low scientific achievement problem. Smart devices, with their contents of students' Applications, may help in math learning.

Through the discussions with the math teachers, the researchers noticed the paucity in the use of the mobile devices in math teaching with reliance on the abstractive and theoretical aspect in teaching the subject. They did not use mobile devices, which are believed to contribute to the simplification and establishment of the concepts in the students' mind, and to save the teachers' time and effort. The researchers also noticed that, in teaching geometrical concepts, most of them were taught using black pencils and discussion, or the way known; as the traditional manner. Usually, the figure or the graphics are drawn on the blackboard with approximate dimensions, without making sure of the accurate measurements, which leads to distortions in the shape of the drawing or the conjunctions (Saha, Ayub \& Tarmizi, 2010). Providing visual Applications; such as GeoGebra and Sketchpad will offer an alternative to overcome these educational shortcomings.

The researchers, through direct contact with the students, found an apparent weakness in their achievement that may be attributed to the low use of modern software, which may contribute to make the student become the focus of the educational process. and add the excitement and interest elements in math learning. Results of many studies such as Verhoef, Coenders, Pieters, van Smaalen and Tall (2015), Leong (2013), and other studies, showed that the use of computer software in math teaching increased the students' achievement levels. For the reasons afore stated, the researchers believe that the use of the applications of the educational mobile devices may assist the teacher in teaching the material. And overcoming the difficulties he/she faces; such as too tight times, abstract nature. and students' traditional view toward math learning.

Within a large number of the educational softwares specialized in the educational topics, the researchers studied the effects of each of Sketchpad and GeoGebra on the university students in the "geometrical concepts" topic. They chose this subject because it needs special skills that take long time and great effort from both of the teacher and student alike; such as graphic representation of the conjunctions, carrying out the overlapping geometrical transformations, studying the conjunction sign and other related topics.

Accordingly, the study problem is represented in answering the following question: What is the effect of the use Mobile Applications (GeoGebra and Sketchpad) on the Students' Achievement of the university students? Therefore, this study aims at comparing the effect of the use of Sketchpad and GeoGebra on the academic achievement, in terms of the conceptual knowledge, procedural knowledge and problem-solving.

The significance of this study stems from adopting modern teaching methods based on the direct practice and application style by the students. They aim at adding the excitement factor as a basic element, in addition to attracting the students' attention to the lecture during application and learning. The significance of the study is also related to the rarity of the studies, which attempted to examine the effect of specialized Applications in math teaching making use of the mobile devices, and comparing between these Applications.

Accordingly, the researchers believe that this study will provide a clear mechanism for the planners and designers of the math curriculum in the university to use a number of educational softwares based on the mobile devices in math teaching. It also offers actual and important results about the best computerized Applications, which may be used in the university education. and may help in setting up educational strategies based on the use of softwares in math teaching and benefiting the available abilities in this area.

\section{METHOD}

The experimental method with a quasi-experimental design was used to explore the impact of using GeoGebra and Sketchpad based on the mobile devices on the students' achievement. This method includes the use of the field experiment, which requires the following three groups:

1- Experimental Group One: consisted of the second year university students, who studied "geometrical concepts" subject using the teaching method based on the use of GeoGebra.

2- Experimental Group Two: consisted of the second year university students, who studied "geometrical concepts" subject using the teaching method based on the use of Sketchpad.

3- Control Group: consisted of the second year university students, who studied "geometrical concepts" subject using the conventional method. 


\section{STUDY POPULATION}

The study was applied to a sample of The Hashemite University Students in Zarqa City (Jordan) during the first semester of the academic year 2018/2019. whose majora are "Class Teacher". The university prepares these students to teach the basic stage pupils from the $1^{\text {st }}$ thru' the $3^{\text {rd }}$ elementary grades. They study geometric concepts; as this subject is one of the obligatory subjects in the BA program. It tackles many geometric concepts and the related properties, theories and laws; such as triangle concept, quadratic shapes, patterns, geometric transformations, and certain conjunctions. The sample was randomly distributed over the study groups: group one $(n=36)$ taught using GeoGebra, group two $(n=35)$ taught using Sketchpad, group three $(n=34)$ taught by the conventional method, and group four $(n=31)$ was designated to verify the validity of the study and its statistical reliability.

\section{GEOMETRIC CONCEPTS SUBJECT}

The researchers phrased the material using Sketchpad and GeoGebra whilst adhering to the study content stipulated in the adopted description of the material by the University. The researchers focused on adopting these Applications as a main way to treat the educational content fully, not only as a supporting educational vehicle of the educational content. The geometric concepts subject were also phrased using the educational Applications, which include introduction of the lecture that contains the concepts listed in it, which usually ends with generalizations. There are also many examples and exercises that include the geometric concepts, formats of conjunctions in algebraic figures, conjunctions in the language of every Application, and forms of the graphic representation of every conjunction or more, using the Application and method of solution as well as "room" for discussion and conclusion. The student's guide was prepared to use each of the Sketchpad and GeoGebra Applications, which included: overview about the Applications, areas of the use of every Application and abilities and the fundamental tools found in it. In addition, it included formation of the conjunctions and carrying out the geometric transformations through them. When the material was fully prepared, it was presented to a number of arbitrators, who were requested to provide their views on paraphrasing the educational objectives in terms of educational, language terminology and skill aspects included in the material, time distribution over the lecture, and math activities. The arbitrators' comments were taken into account and implemented.

\section{ACHIEVEMENT TEST}

The researchers analyzed the content of the geometric concepts, and constructed their table of specifications. Consequently, the achievement test was made depending on the table of specifications. The test consisted of 50 items of the kind of multiple choices, which takes into consideration the National Assessment of Educational Progress (NAEP) levels of the educational objectives. Namely: conceptual knowledge, procedural knowledge and problem solving. The test validity was verified by presenting it to a pool of arbitrators who were requested to provide their views and suggestion, upon which the test was amended. The researchers applied the test to an exploratory sample and calculated the difficulty coefficients, which ranged between 0.32 and 0.75 , and the discrimination coefficients, which were between 0.24 and 0.79 . The test reliability was verified through Cronbach Alpha, which amounted (0.85), representing an educationally acceptable value.

\section{STUDY APPLICATION MECHANISM}

1- Teaching using the Application: the researchers showed the students how to download each of GeoGebra and Sketchpad on the mobile or iPad. In addition, the researchers provided internet using a mobile WiFi as well as data show devices. In preparation for applying the study, the researchers delivered two consecutive lectures to the three groups, where the educational Applications guide was distributed over the experimental groups as per their Applications. The lectures included an overview about every Application, how to use it and how to phrase the geometric concepts using the Application. On the other hand, for achieving the parity principle, the third group (control group) was given two lectures as a revision of certain geometric concepts, conjunction representation and reviewing the famous conjunctions, which the students experienced in the past.

2- Students of class teacher major were taught according to the Application designated for every group. In the beginning of every lecture, the researchers explained a certain part of the material through 
Table 1. M's and SD's of the Three Groups

\begin{tabular}{lllll}
\hline Variable & Group & No. & M & SD \\
\hline \multirow{2}{*}{ Conceptual Knowledge } & GeoGebra Group & 36 & 16.04 & 0.70 \\
\cline { 2 - 5 } & Sketchpad Group & 35 & 14.27 & 0.82 \\
\cline { 2 - 5 } Procedural Knowledge & Control Group & 34 & 11.86 & 0.61 \\
\hline \multirow{3}{*}{ Problem Solving } & GeoGebra Group & 36 & 15.31 & 0.71 \\
\cline { 2 - 5 } & Sketchpad Group & 35 & 13.16 & 0.73 \\
\cline { 2 - 5 } & Control Group & 34 & 11.70 & 0.86 \\
\hline \multirow{3}{*}{ Overall Test } & GeoGebra Group & 36 & 13.65 & 1.07 \\
\cline { 2 - 5 } & Sketchpad Group & 35 & 11.80 & 1.26 \\
\cline { 2 - 5 } & Control Group & 34 & 10.40 & 1.46 \\
\cline { 2 - 5 } & GeoGebra Group & 36 & 39.23 & 1.18 \\
\cline { 2 - 5 } & Sketchpad Group & 35 & 33.96 & \\
\hline
\end{tabular}

application using the Application, which is displayed on the students' screen directly. Sometimes, they sought the help of the data show to write the explanations or any other notes about the graphic drawings. Subsequently, the students were allowed to apply what they learnt using every Application, through solving the exercises and the problems contained in the material, or what the researchers added according to the lesson requirements and its teaching methods.

3- The students were left a wide "margin" to interact with the educational applications so that the lectures were allocated as follows; in the first a lecture, where the instructor has a wide role in teaching the material using the Application then the student applies the examples, the instructor explained and certain exercises included in the material. In the second lecture, students are given a wide space to solve all the exercises, and the problems stated in the material, or what the researches ask them to do.

\section{GROUP PARITY}

To assure the parity, intergroup Wilkes Lambda value was calculated, which was $0.992 ; \mathrm{F}$ value was 0.13 and the statistical significance was 0.99 , which indicates nonexistence of differences between the three groups in the pre-application of the achievement test. This result illustrated that the students in the control and experimental groups were similar in achievement before the treatment was administered.

\section{RESULTS}

The findings of this study are discussed based on the objectives stated. Analyses of the post-test achievement scores were conducted. There were differences in the achievement test score means between students utilizing GeoGebra, Sketchpad and conventional instruction. The group taught using GeoGebra had the following results: the students' achievement means in the conceptual knowledge, procedural knowledge, problem solving and overall all test were: (16.04), (15.31), (13.65), and (45.01) respectively. Students' achievement means of the group taught using Sketchpad in the conceptual knowledge, procedural knowledge, problem solving and overall all test were: (14.27), (13.16), (11.80) and (29.23), respectively. Finally, students' achievement means of the group taught using conventional method in the conceptual knowledge, procedural knowledge, problem solving and overall all test were: (11.86), (11.70), (10.40) and (33.96), respectively. Table 1 illustrates these results.

To verify the significance of the differences, we calculated Wilkes Lambda value, which was 0.315 , the opposite F value, which was 26.08, and the significance, which was (0.00), indicative of the existence of differences between the study groups. The multiple analysis of variance (MANOVA) was employed, which results showed differences in the students' achievement as follows: In the conceptual knowledge: $\mathrm{F}=44.456$ $(\mathrm{p}<0.05)$; in the procedural knowledge: $\mathrm{F}=29.189(\mathrm{p}<0.05)$; in problem solving: $\mathrm{F}=19.136(\mathrm{p}<0.05)$; and, in the overall test: $\mathrm{F}=92.459(\mathrm{p}<0.05)$, as shown in Table 2 . 
Table 2. MANOVA to Identify the Significance of the Differences among the Means of the Three Groups

\begin{tabular}{llccccc}
\hline Source & Dependent Variable & $\begin{array}{c}\text { Type III Sum } \\
\text { of Squares }\end{array}$ & DF & M. Square & F & Sig \\
\hline \multirow{3}{*}{$\begin{array}{l}\text { Teaching } \\
\text { Method }\end{array}$} & Conceptual Knowledge & 307.152 & 2 & 153.576 & 44.456 & 0.00 \\
\cline { 2 - 7 } & Procedural Knowledge & 231.911 & 2 & 115.955 & 29.189 & 0.00 \\
\cline { 2 - 7 } & Problem Solving & 186.270 & 2 & 93.135 & 19.136 & 0.00 \\
\cline { 2 - 7 } & Overall Test & 2135.662 & 2 & 1067.831 & 92.459 & 0.00 \\
\cline { 2 - 7 } Error & Conceptual Knowledge & 352.366 & 102 & 3.455 & 44.456 \\
& Procedural Knowledge & 405.203 & 102 & 3.973 & 29.189 \\
\cline { 2 - 7 } & Problem Solving & 496.425 & 102 & 4.867 & 19.136 \\
\hline
\end{tabular}

Table 3. LSD Results of the Post Hoc Binary Comparisons

\begin{tabular}{|c|c|c|c|c|c|}
\hline $\begin{array}{l}\text { Dependent } \\
\text { Variable }\end{array}$ & (I) VAR & (J) VAR & Mean Difference & $\begin{array}{l}\text { Std. } \\
\text { Error }\end{array}$ & Sig. \\
\hline \multirow{3}{*}{$\begin{array}{l}\text { Conceptual } \\
\text { Knowledge }\end{array}$} & \multirow[b]{2}{*}{ GeoGebra Group } & Sketchpad Group & 0.68 & 017 & 0.00 \\
\hline & & Control Group & 1.61 & 017 & 0.00 \\
\hline & Sketchpad Group & Control Group & 0.93 & 0.17 & 0.00 \\
\hline \multirow{3}{*}{$\begin{array}{l}\text { Procedural } \\
\text { Knowledge }\end{array}$} & \multirow{2}{*}{ GeoGebra Group } & Sketchpad Group & 0.83 & 0.18 & 0.00 \\
\hline & & Control Group & 1.39 & 0.18 & 0.00 \\
\hline & Sketchpad Group & Control Group & 0.557 & 0.19 & 0.003 \\
\hline \multirow{3}{*}{ Problem Solving } & \multirow{2}{*}{ GeoGebra Group } & Sketchpad Group & 0.71 & 0.20 & 0.00 \\
\hline & & Control Group & 1.25 & 0.20 & 0.00 \\
\hline & Sketchpad Group & Control Group & 0.54 & 0.20 & 0.01 \\
\hline \multirow[t]{3}{*}{ Overall Test } & \multirow{2}{*}{ GeoGebra Group } & Sketchpad Group & 2.22 & 0.31 & 0.00 \\
\hline & & Control Group & 4.25 & 0.31 & 0.00 \\
\hline & Sketchpad Group & Control Group & 2.03 & 0.31 & 0.00 \\
\hline
\end{tabular}

To identify the significance of the differences, the researchers used the least significance difference (LSD). The results showed the students of the group taught using GeoGebra outperformed the experimental group students, who were taught using Sketchpad, and still outperformed the control group students, who were taught using the conventional method. This preeminence was in all the dependent variables (conceptual knowledge, procedural knowledge, problem solving and the overall test). furthermore, the results showed the supremacy of the experimental group students, who were taught using Sketchpad over the control group, who received teaching using the conventional method, in all the above mentioned four dependent variables shown in Table 3.

\section{DISCUSSION}

The researchers explain the positive effect of GeoGebra and Sketchpad based on mobile devices "at the cost of" the conventional method to the multiple advantages of the use of the mobile devices appliances. These educational applications offer advantages and tools, which may have enabled the student interact directly with the educational content. The student, through these devices, was able to represent the conjunctions graphically, carry out the suitable and overlapping geometric transformations, control the properties of the graphic drawing panel, change the background color, and control the size of the lines in the figure the way he/she deems fit. As a result, these applications fostered the learning process by practice, so that the student became the focus of the educational process.

GeoGebra and Sketchpad based on mobile devices contributed in supporting the student actively to acquire knowledge, because of the large amounts of scientific knowledge these devices can provide. They increase the students focus on the educational content, his/her positive interaction in doing the exercise, problems and duties, and develop the students' ability to use these modern Applications optimally in their school education. In addition, these Applications saved many efforts spent to acquire the learning basic skills as compared to the conventional method used in teaching mathematics, particularly, in the graphic drawings area. Therefore, applying these examples, exercises and questions through these Applications was characterized by easiness and simplicity. This was reflected on the large amount of exercises and questions that enable the student 
apply and solve them in relatively shorter time and less effort, which, in turn, enrich the student's learning, establish the information in his/her mind, and lessen his/her study burden.

These Applications also offered new method in math learning, which attracted the interest of the students, who were taught using the Applications, and drew their attention in the lectures and made them focus on problem solving. Therefore, they provided them a fertile environment for math learning. The researchers see that these Applications are characterized by the high accuracy they provide in the graphic representation, carrying out the geometric transformations, control over curve drawing, and representing the different conjunctions. In addition, they are characterized by providing feedback that helps students correct their work instantly and easily. Thereby, they contributed to their learning correctly and soundly. For these reasons, the researchers believe that these softwares contributed in increasing the students' degrees in the achievement posttest between the two experimental groups where students used Sketchpad and GeoGebra, at the cost of the group where students used the conventional method. The results of this study are in line with the results of (Arbain \& Shukor,2015; Bhagat \& Chang,2015; Diković,2009; Gemechu,2017; Leong,2013; Shadaan \& Leong, 2013; Teoh \& Fong,2005).

The researchers attribute the supremacy of the group taught using GeoGebra over the group taught using Sketchpad to that GeoGebra contains drawing orders that are easily implemented, than Sketchpad, an aspect that is clear in the geometric transformations. Furthermore, users of GeoGebra owned the skill of easy dealing and possibility of controlling the drawing with accuracy and mastering, because the GeoGebra contains the properties order that performs a distinguished role in controlling the drawing, as compared with Sketchpad

Furthermore, GeoGebra contains orders that implement the potential of measurement and algebra with all skill, ease and mastery, which not found in Sketchpad, In addition, GeoGebra has algebraic orders that are performed at high professional degree. The reason of the outperformance of the group that used GeoGebra is that Sketchpad does not possess the potential to combine algebraic inputs and the geometric display, which is one of the advantages of GeoGebra that distinguishes it from Sketchpad. This result is in line with those of (Hellebrands, 2007; Tomić, 2013).

\section{CONCLUSIONS}

This study provides teachers an alternative to use applications of the mobile devices in teaching math as a tool in their teaching activities. Students can download these Applications and use them at homes. Usually, the cost may be the decisive factor to obtain new educational means in learning, in order to the open resource softwares to solve the problems that do not require cost. Therefore, the math teachers are advised to use GeoGebra and Sketchpad in the teaching process.

The Applications provide both, the teachers and students, a new free tool, which is a new method to use technology with visual means to help the students interact with the mathematical concepts individually or in groups, in the classrooms, at homes or in another more suitable place, as the students and teachers needs may require when using these mobile devices. These devices could be used as tools for complementary activities to prepare the normal semesters, where students can obtain prompt reactions from the results they reached in the semester activities and in their homework.

Math learning-teaching should not focus on the pure theories. Rather, they should focus on varieties of learning methods that include the educational means, which were proved helpful in motivating the students' interest in mathematics. The math Application, available in the market or even online, facilitated the teacher's task in transmitting meaningful knowledge to the students. Nonetheless, it is for the teacher to use the materials that are readily available, without allocating additional time to develop the other educational means.

Definitely, this study showed that GeoGebra and Sketchpad have positive effects on the students' achievement. These Applications should be introduced to the math teachers so that students become able to explore the math world more widely and deeply, and make them able to think critically and creatively.

\section{Disclosure statement}

No potential conflict of interest was reported by the authors. 


\section{Notes on contributors}

Mohammad Ahmad Alkhateeb - Hashemite University, Zarqa, Jordan.

Ahmed Mohammad Al-Duwairi - AL- Albayt University, Mafraq, Jordan.

\section{REFERENCES}

Abramovich, S. (2013). Computers in Mathematics Education: An Introduction. Computers in the Schools, 30(1-2), 4-11. https://doi.org/10.1080/07380569.2013.765305

Arbain, N., \& Shukor, N. (2015). The effects of GeoGebra on students' achievement. Procedia-Social and Behavioral Sciences, 172, 208-214. https://doi.org/10.1016/j.sbspro.2015.01.356

Baki, A., Kosa, T., \& Guven, B. (2011). A comparative study of the effects of using dynamic geometry software and physical manipulative on the spatial visualization skills of pre - service mathematics teachers. British Journal of Educational Technology, 42(2), 291-310. https://doi.org/10.1111/j.14678535.2009.01012.x

Bhagat, K., \& Chang, C. (2015). Incorporating GeoGebra into Geometry learning-A lesson from India. Eurasia Journal of Mathematics, Science \& Technology Education, 11(1), 77-86. https://doi.org/10.12973/eurasia.2015.1307a

Chaamwe, N. (2010). Integrating ICTS in the teaching and learning of mathematics: an Overview, 2nd International Workshop on Education Technology and Computer Science, (pp. 397-400). https://doi.org/10.1109/ETCS.2010.163

Dias, L., \& Victor, A. (2017). Teaching and Learning with Mobile Devices in the 21st Century Digital World: Benefits and Challenges. European Journal of Multidisciplinary Studies, 2(5), 340-345. Retrieved from http://journals.euser.org/files/articles/ejms_may_aug_17/Lina2.pdf

Diković, L. (2009). Applications GeoGebra into teaching some topics of mathematics at the college level. Computer Science and Information Systems, 6(2), 191-203. https://doi.org/10.2298/csis0902191D

Emaikwu, S., Lji, C., \& Abari, M. (2015). Effect of GeoGebra on Senior Secondary School Students' Interest and Achievement in Statistics in Makurdi Local Government Area of Benue State Nigeria. Journal of Mathematics (IOSRJM), 2(3), 14-21. https://doi.org/10.9790/5728-11341421

Galligan, L., Loch, B., McDonald, C., \& Taylor, J. A. (2010). The use of tablet and related technologies in mathematics teaching. Australian Senior Mathematics Journal, 24(1), 38-51

Gecu, Z., \& Satici, A. (2012). The effects of using digital photographs at 4th Grade. Procedia - Social and Behavioral Sciences, 46(2012), 1956-1960. https://doi.org/10.1016/j.sbspro.2012.05.410

Gemechu, D. (2017). The effect of geometry sketchpad on the academic achievement of students: the case of beadle secondary and preparatory school. International journal of engineering sciences \& research technology, 6(5), 29-39. https://doi.org/10.5281/zenodo.571592

Grant, M., Tamim, S., Brown, D., Sweeney, J., Ferguson, F., \& Jones, L. (2015). Teaching and learning with mobile computing devices: Case study in K-12 classrooms. TechTrends: Linking Research and Practice to Improve Learning, 59(4), 32-45. https://doi.org/10.1007/s11528-015-0869-3

Gürsul, F. \&. Keser, H. (2009). The effects of online and face-to-face problem based learning environments in mathematics education on student's academic achievement. Procedia-Social and Behavioral Sciences, 1(1), 2817-2824. https://doi.org/10.1016/j.sbspro.2009.01.501

Hohenwarter, M., \& Lavicza, Z. (2007). Mathematics teacher development with ICT: towards an International GeoGebra Institute. Proceedings of the British Society for Research into Learning Mathematics, 27(3), 49-54.

Hollebrands, K. (2007). The Role of a Dynamic Software Program for Geometry in the Strategies High School Mathematics Students Employ. Journal for Research in Mathematics Education, 38(2), 164-192. Retrieved from https://www.jstor.org/stable/30034955?seq=1\#page_scan_tab_contents

Kebritchi, M., Hirumi, A. \& Bai, H. (2010). The effects of modern mathematics computer games on mathematics achievement and class motivation. Computers \& education, 55(2), 427-443. https://doi.org/10.1016/j.compedu.2010.02.007

Korenova, L. (2012). The use of a digital environment for developing the creativity of mathematically gifted high school students. 12th International Congress on Mathematical Education, Seoul, Korea. 
Leong, K. (2013). Impact of Geometer's Sketchpad on students achievement in graph functions. The Malaysian Online Journal of Educational Technology, 1(2), 19-31. Retrieved from https://files.eric.ed.gov/fulltext/EJ1086502.pdf

Li, Q., \& Ma, X. (2010). A meta-analysis of the effects of computer technology on school students' mathematics learning. Educational Psychology Review, 22(3), 215-243. https://doi.org/10.1007/s10648-010-9125-8

Li, Q. (2007). Student and teacher views about technology: A tale of two cities? Journal of research on Technology in Education, 39(4), 377-397. Retrieved from https://files.eric.ed.gov/fulltext/EJ768884.pdf

National Council of Teachers of Mathematics. (2000). Principles and standards for school mathematics. Reston, VA: Author.

Ruthven, K., \& Hennessy, S. (2002). A practitioner model of the use of computer-based tools and resources to support mathematics teaching and learning. Educational studies in mathematics, 49(1), 47-88.

Saha, R., Ayub, A. \& Tarmizi, R. (2010). The effects of GeoGebra on mathematics achievement: enlightening coordinate geometry learning. Procedia-Social and Behavioral Sciences, 8, 686-693. https://doi.org/10.1016/j.sbspro.2010.12.095

Shadaan, P., \& Leong, K. (2013). Effectiveness of Using GeoGebra on Students' Understanding in Learning Circles. Malaysian Online Journal of Educational Technology, 1(4), 1-11. http://www.mojet.net/frontend/articles/pdf/v01i04/v01i04-01.pdf

Supandi, L., Ariyanto, W., Kusumaningsih, \& An, A. (2017). Mobile phone application for mathematics learning. IOP Conf. Series: Journal of Physics: Conf. Series. 983(2018), 012106. https://doi.org/10.1088/1742-6596/983/1/012106

Teoh, B., \& Fong, S. (2005). The Effects of Geometer's Sketchpad and Graphic Calculator in the Malaysian Mathematics Classroom. Malaysian Online Journal of Instructional Technology, 2, 82-96. Retrieved from http://citeseerx.ist.psu.edu/viewdoc/download?doi=10.1.1.116.8520\&rep=rep1\&type=pdf

Thomas, K., \& Muñoz, M. (2016). Hold the Phone! High School Students' Perceptions of Mobile Phone Integration in the Classroom. American Secondary Education, 44(3), 19-37. Retrieved from https://www.ashland.edu/coe/about-college/american-secondary-education-journal

Tomić, M. (2013). Mathematical Software in Croatian Mathematics Classrooms - A Review of GeoGebra and Sketchpad. Croatian Journal of Education, 15(1/2013), 197-208.

Verhoef, N., Coenders, F., Pieters, J., van Smaalen, D., \& Tall, D. (2015). Professional development through lesson study: teaching the derivative using GeoGebra. Professional development in education, 41(1), 109-126. https://doi.org/10.1080/19415257.2014.886285

Walker, R. (2013). I don't think I would be where I am right now. Pupil perspectives on using mobile devices for learning, Research in Learning Technology, 21, 1-12. https://doi.org/10.3402/rlt.v21i2.22116

Zakaria, E., \& Lee, L. (2012). Teachers' perceptions toward the use of GeoGebra in the teaching and learning of mathematics. Journal of Mathematics and Statistics, 8(2), 253-257. https://doi.org/10.3844/jmssp.2012.253.257

Zaranis, N., Kalogiannakis, M., \& Papadakis, S. (2013). Using Mobile Devices for Teaching Realistic Mathematics in Kindergarten Education. Creative Education, 4(7), 1-10. https://doi.org/10.4236/ce.2013.47A1001

Zengin, Y., Furkan, H., \& Kutluca, T. (2012). The effect of dynamics mathematics software GeoGebra on student achievement in teaching of trigonometry. Procedia Social and Behavioral Sciences, 31, 183187. Retrieved from https://pdfs.semanticscholar.org/71e6/c4c7cb2802143c7edeefb0de43987ccbe85.pdf

Zhao, X., \& Okamoto, T. (2009). A Personalized Mobile Mathematics Tutoring System for Primary Education. Journal of the Research Center for Educational Technology, 4(1), 61-67. 